\title{
Prevalence of gingivitis and periodontitis among schools children in Lucknow region of Uttar Pradesh, India.
}

\author{
Dr. Awadhesh Kumar Singh \\ Periodontology, Chandra Dental College \& Hospital, Safedabad, Barabanki, Uttar Pradesh, India.
}

\begin{abstract}
:
Background: This initiative is a consequence of the absence of recent information since studies being conducted much before in the past on the prevalence of gingivitis and periodontitis among schools children in Lucknow region of Uttar Pradesh, India.

Aims and Objectives: To assess the prevalence of gingivitis and periodontitis among schools children and evaluating the pattern of these diseases in different age groups among them.

Setting and Design: It was a cross-sectional study done in Lucknow region of Uttar Pradesh, India.

Subjects \& Methods: A total of 650 school going children were examined, 225 children were in 8-10 years age group and $215 \& 210$ children were in the age group of $11-14$ years \& $15-17$ years, respectively. The gingival index, given by Loe \& Silness was used for recording the severity of gingivitis and periodontal disease index, given by Ramfjord was used for evaluating periodontitis.

Result: The prevalence of gingivitis and periodontitis were $77.52 \%$ and $16.03 \%$, respectively.

Conclusion:

The overall prevalence of gingivitis and periodontitis were $77.52 \%$ and $16.03 \%$, respectively among schools children of 8 to 17 years of age in Lucknow region of Uttar Pradesh, India. The younger age group children had comparatively lesser percentage of gingivitis and periodontitis than older age group children.
\end{abstract}

Keywords: Gingivitis, periodontitis, prevalence.

\section{Introduction}

Many epidemiological studies have been conducted from time to time by dental professional among schools children regarding periodontal diseases in different parts of India. These epidemiological studies are helpful in planning and implementing oral health programs. This would help the nation in combating these diseases. Periodontal diseases including gingivitis and periodontitis are serious infection that if left untreated can lead to tooth loss. Gingivitis is reversible with professional treatment and good oral home care, whereas periodontitis is irreversible as this progress with destruction of bone. Untreated gingivitis can advance to periodontitis. Hence if gingivitis and periodontitis are assessed in an early stage it will minimize the chance of tooth loss. The aim of this study was to assess the prevalence of gingivitis and periodontitis among schools children in Lucknow region of Uttar Pradesh, India and evaluating the pattern of these diseases in different age groups among them.

\section{Materials And Methods}

This study was cross-sectional in nature and conducted in Lucknow region of Uttar Pradesh, India. The study was carried out over a period of 6 months between the months of December 2012 \& April 2013. A sample size of 650 school going children from 3 schools located in Lucknow region was examined. These schools were randomly selected. Written permission was obtained from school authorities. Only children who were permanent resident of Lucknow region and who were available on day of examination were included in the study. Children were examined in their respective school on pre-decided dates.

The examinations were carried out in broad day-light. Children were seated on ordinary chair in upright position. Intraoral examinations were made using mouth mirror and UNC-15 probe. Instruments were disinfected with an antiseptic solution after every use and antiseptic solutions were change frequently between the examinations.

The gingival index, given by Loe and Silness [1] was used for recording the severity of gingivitis and periodontal disease index, given by Ramfjord [2] was used for evaluating periodontitis. Gingival index, given by Loe and Silness measures severity of gingivitis on a scale ranging from 0.1 to 3.0 (0.1-1.0: mild gingivitis, 1.12.0: moderate gingivitis, and 2.1-3.0: severe gingivitis).

Periodontal component of periodontal disease index, given by Ramfjord [2] measures severity of periodontitis on a scale ranging from 4 to 6 (4: gingival crevicular depth from CEJ is up to $3 \mathrm{~mm}$, 5: gingival crevicular depth from CEJ is 3-6 mm, and 6: gingival crevicular depth from CEJ is more than $6 \mathrm{~mm}$ ). 
Among 650 children, 225 were in the age group of 8-10 years, 215 were in the age group of 11-14 years and 210 were in the age group of $15-17$ years.

\section{Results}

A total of 650 school going children were examined in this study, out of them 225 children belong to age group 8-10 years and $215 \& 210$ children to the age group 11-14 years and 15-17 years, respectively [Table $1]$.

The overall prevalence of gingivitis [Table 2] was $77.52 \%$ (mild gingivitis: $57.94 \%$, moderate gingivitis: $17.4 \%$ and severe gingivitis: $2.1 \%$ ). In $8-10$ years old, gingivitis prevalence was $71.11 \%$ (mild gingivitis: $53.33 \%$, moderate gingivitis: $16.44 \%$ and severe gingivitis: $1.33 \%$ ). In $10-14$ years old, gingivitis prevalence was $78.13 \%$ (mild gingivitis: $58.13 \%$, moderate gingivitis: $17.67 \%$ \& severe gingivitis: $2.32 \%$ ). In 15-17 years old, gingivitis prevalence was $83.33 \%$ (mild gingivitis: $62.38 \%$, moderate gingivitis: $18.09 \%$ and severe gingivitis: $2.85 \%)$. The average healthy gingiva was $22.46 \%$ (22.88\% in $8-10$ years, $21.86 \%$ in $11-14$ years \& $16.66 \%$ in $15-17$ years age group).

The total prevalence of periodontitis [Table 3] was $16.03 \%$ (13.69\% had score $4,1.55 \%$ had score $5 \&$ $0.77 \%$ had score 6$)$. In $8-10$ years old, prevalence of periodontitis was $8 \%(6.66 \%$ had score $4,0.88 \%$ had score $5 \& 0.44 \%$ had score 6$)$. In $11-14$ years old, prevalence of periodontitis was $15.34 \%$ (13.48\% had score 4 , $1.39 \%$ had score $5 \& 0.46 \%$ had score 6$)$. In $15-17$ years old, prevalence of periodontitis was $24.76 \%$ (20.95\% had score $4,2.38 \%$ had score $5 \& 1.42 \%$ had score 6$)$. The average healthy periodontium was $83.96 \%(92 \%$ in $8-10$ years, $84.65 \%$ in $11-14$ years and $75.23 \%$ in $15-17$ years age group).

\section{Discussion}

School going children were targeted in this study for ease of accessibility [3]. The gingival index, given by Loe and Silness [1] was use to assess the severity of gingivitis. The overall gingivitis was $77.52 \%$ which] increased with age, as was observed by Jose et al. [4] in 2003, Kumar et al. [5] in 2005 and Dhar et al. [6] in 2007. The periodontal disease index, given by Ramfjord [2] was used to evaluate periodontitis. Overall periodontitis was $16.03 \%$ which also increased with age.

Our findings were close to the findings of Gill and Prasad [7] who in 1968 reported 83\% gingivitis and $18.2 \%$ periodontitis among schools children in Lucknow. They also reported that younger age group had comparatively lesser percentage of gingivitis \& periodontitis which were also similar to our study. Our findings also support the finding of Nanda RS et al. [8] in 1969 that used Glickman's method of periodontal examination and examined 1253 school children aged between 4 to 17 years in Lucknow. Their results indicated that prevalence of gingivitis increased with age. Highest prevalence was found in the 12-14 years age group. A similar finding to our finding were reported by Singh et al. [9] in 1985 who examined 141 subjects aged 15-40 years in Lucknow and concluded that prevalence of absolute pocket increased with age.

Our findings contradict the findings of Chawla TN [10] who in 1963 reported 100\% gingivitis and $72.2 \%$ periodontitis in a sample of 259 subjects in the age group 12 to 17 years in Lucknow. Mathur SK and Roy RK [11] in 1981 examined 1200 children aged 3 to 14 years from Lucknow. They reported that $100 \%$ of children had gingivitis which is also not in accordance with our findings.

Information provided by the present study for prevalence of gingivitis and periodontitis can be used as preliminary data and further large scale epidemiological studies can be under taken to assess and confirm other dental diseases and their associated risk factors in Lucknow region of Uttar Pradesh, India. School dental health programs and dental camps at school level are necessary in this region and they should be conducted at regular intervals, because children in this region do not have accessed to standard dental care and treatment. Because schools children do not know much about dental diseases, methods of their prevention and to maintain proper oral hygiene, therefore education and motivation of children is of paramount important in this region. Teachers and parents should be taught and encourage to enculate healthy life style habits in children. The more important aspect is the management of dental fear which is a worldwide problem and universal barrier to oral health care services should be covered in school dental health programs. Fears acquired in childhood through direct experience with painful dental treatment or vicariously through parents, friends or siblings may persist in adulthood. Lack of pain control and sympathy with children may exacerbate fears. The behavioral child management technique along with preventive dentistry should be a fundamental part of school dental health programs.

\section{Conclusion}

The overall prevalence of gingivitis and periodontitis were $77.52 \%$ and $16.03 \%$, respectively among schools children of 8 to 17 years of age in Lucknow region of Uttar Pradesh, India. The younger age group children had comparatively lesser percentage of gingivitis and periodontitis than older age group children. 


\section{References}

[1]. H. Loe, J. Silness, Periodontal disease in pregnancy. 1. Prevalence and severity, Acta Odontol Scand, 21, 1963, 53

[2]. SP Ramfjord, Indices for prevalence and incidence of periodontal disease, J Periodontol 30, 1959, 51

[3]. AK Holm, Caries in preschool children-international trends, J Dent 18, 1990, 291-295.

[4]. A. Jose, MR Joseph, Prevalence of dental health problems among school going children in rural Kerala. J Indian Soc Pedod Prev Dent 21, 2003, 147-151.

[5]. MP Kumar, T Joseph, RB Varma, M Jayanth, Oral health status of 5 years and 12 years schools going children in Chennai city: An epidemiological study, J Indian Soc Pedod Prev Dent 23, 2005, 17-22.

[6]. V Dhar, A Jain, TE Van Dyke, A Kohli, Prevalence of gingival disease in school going children of rural areas in Udaipur District, J Indian Soc Pedod Prev Dent 25, 2007,103-105.

[7]. D. Marshall, as quoted in national oral health policy for India, J Ind Dent Ass 50, 1986, 378-401.

[8]. SS Hiremath, Epidemiology of periodontal diseases, in SS Hiremath, (Ed.), Textbook of Preventive and Community Dentistry, 2 (New Delhi: Elsevier press, 2011) 153.

[9]. S Peter, DG Nayak, Epidemiology, etiology and prevention of periodontal diseases, in S Peter,(Ed.), Essentials of Preventive and Community Dentistry, 2 (New Delhi: Arya (Medi) press, 2006) 430

[10]. TN Chawla, RS Nanda, MC Mathur, Prevalence of periodontal disease in urban Lucknow, India, Using Ramfjord technique. J All Ind Dent Ass 35, 1963, 151-156.

[11]. S Peter, DG Nayak, Epidemiology, etiology and prevention of periodontal diseases, in S Peter, (Ed.), Essentials of Preventive and Community Dentistry. 2 (New Delhi: Arya (Medi) press, 2006) 428.

Table 1: Demographic data

\begin{tabular}{|l|l|}
\hline Age group & No. of children \\
\hline $8-10$ years & 225 \\
\hline $11-14$ years & 215 \\
\hline $15-17$ years & 210 \\
\hline Total & 650 \\
\hline
\end{tabular}

Table 2: Gingivitis

\begin{tabular}{|l|l|l|l|l|l|l|}
\hline Age group & $\begin{array}{l}\text { Total no. of } \\
\text { children }\end{array}$ & Normal & $\begin{array}{l}\text { Total no. of } \\
\text { affected }\end{array}$ & Mild gingivitis & $\begin{array}{l}\text { Moderate } \\
\text { gingivitis }\end{array}$ & $\begin{array}{l}\text { Severe } \\
\text { gingivitis }\end{array}$ \\
\hline $8-10$ years & 225 & $65(28.88 \%)$ & $160(71.11 \%)$ & $120(53.33 \%)$ & $37(16.44 \%)$ \\
\hline $11-14$ years & 215 & $47(21.86 \%)$ & $168(78.13 \%)$ & $125(58.13 \%)$ & $38(17.67 \%)$ & $5(2.32 \%)$ \\
\hline $15-17$ years & 210 & $35(16.66 \%)$ & $175(83.33 \%)$ & $131(62.38 \%)$ & $38(18.09 \%)$ & $6(2.85 \%)$ \\
\hline Total & 650 & $147(22.46 \%)$ & $503(77.52 \%)$ & $376(57.94 \%)$ & $113(17.4 \%)$ \\
\hline
\end{tabular}

Table 3: Periodontitis

\begin{tabular}{|l|l|l|l|l|l|l|}
\hline Age group & $\begin{array}{l}\text { Total no. of } \\
\text { children }\end{array}$ & Normal & $\begin{array}{l}\text { Total no. of } \\
\text { affected }\end{array}$ & \multicolumn{2}{|l|}{ PDI scores in \% } \\
\cline { 4 - 7 } & & & 4 & 5 & 6 \\
\hline $8-10$ years & 225 & $207(92 \%)$ & $18(8 \%)$ & $15(6.66 \%)$ & $2(0.88 \%)$ \\
\hline $11-14$ years & 215 & $182(84.65 \%)$ & $33(15.34 \%)$ & $29(13.48 \%)$ & $3(1.39 \%)$ \\
\hline $15-17$ years & 210 & $158(75.23 \%)$ & $52(24.76 \%)$ & $44(20.95 \%)$ & $5(2.38 \%)$ & $1(0.46 \%)$ \\
\hline Total & 650 & $547(83.96 \%)$ & $103(16.03 \%)$ & $88(13.69 \%)$ & $10(1.55 \%)$ \\
\hline
\end{tabular}

*PDI: - Periodontal disease index. 